\title{
The plasma cell associated antigen detectable by antibody VS38 is the p63 rough endoplasmic reticulum protein
}

\author{
A H Banham, H Turley, K Pulford, K Gatter, D Y Mason
}

\begin{abstract}
Aims-To characterise the $64 \mathrm{kDa}$ intracellular antigen present on normal and neoplastic plasma cells detected by monoclonal antibody VS38 and by another antibody, MC186, of similar reactivity.

Methods-The VS38 monoclonal antibody was used to screen a bacterially expressed peripheral blood cDNA library, and the immunocytochemical staining of the two antibodies was compared with those raised specifically to the protein identified as the VS38 antigen.

Results-A partial cDNA encoding the VS38 antigen was cloned and shown to be identical to the human p63 gene. p63 is a non-glycated, reversibly palmitoylated type II transmembrane protein which is found in rough endoplasmic reticulum. Antibody MC186 also recognised this protein and both VS38 and MC186 together with two antibodies raised to p63 gave identical immunostaining patterns.

Conclusions-The VS38 antigen was identified as the rough endoplasmic reticulum protein p63. While it is not exclusively expressed on plasma cells, the presence of p63 distinguishes plasma cells from other lymphoid cells because of their high secretory activity.

(f Clin Pathol 1997;50:485-489)
\end{abstract}

Keywords: plasma cell; p63; rough endoplasmic reticulum

University of Oxford, Department of Cellular Science, John Radcliffe Hospital, Oxford, United Kingdom

A H Banham

$\mathrm{H}$ Turley

K Pulford

K Gatter

D Y Mason

Correspondence to: Dr Alison Banham, University of Oxford, Department of Cellular Science, Level 5, room 5501, John Radcliffe Hospital,
Headington, Oxfordshire OX3 9DU

email: abanham $a$ worf. molbiol.ox.ac.uk

Accepted for publication 10 March 1997
Plasma cells represent the terminal stage of B cell differentiation and contain prominent rough surfaced endoplasmic reticulum within which immunoglobulin is synthesised. Although derived from B cells, plasma cells lose most of the antigens associated with this lineage, for example surface immunoglobulin, CD19, or CD20. Other antigens appear at this for plasma cells, and there are no antibodies to these markers that detect all normal and neoplastic plasma cells and also work on routinely preserved specimens. ${ }^{1-6}$

VS38 is a previously characterised mouse monoclonal antibody which reacts with a formalin resistant epitope expressed strongly by both normal and neoplastic plasma cells but not by haemopoietic cells of other lineages. ${ }^{7}$ The antigen is also expressed to some extent in both normal and neoplastic epithelial cells. We describe here the expression cloning of a stage of B cell maturation but none is specific
cDNA encoding the epitope recognised by the VS38 antibody and show that the antigen is a previously characterised human protein, $\mathrm{p} 63 .{ }^{8}$ We also show that a second antibody from our laboratory, MC186, recognises the VS38 antigen, and that the immunostaining of this antibody and of VS38 is identical to that of two additional antibodies raised against the p63 protein.

\section{Methods}

IMMUNOLOGICAL CDNA LIBRARY SCREENING

An oligo dT and random primed cDNA library from circulating blood in lambda ZAP Express was purchased from Stratagene (Cambridge, UK). Ten thousand plaques per $15 \mathrm{~cm}$ plate were grown on Escherichia coli strain XL1 Blue MRF' (Stratagene) and protein expression was induced by overlaying IPTG soaked filters as described previously. ${ }^{10}$ Filters were removed next day (after approximately 16 hours) and rinsed in PBST (phosphate buffered saline $+0.05 \%$ Tween 20 ) for five minutes. Filters were washed in fresh PBST for 30 minutes before blocking in PBST $+5 \%$ Marvel at room temperature for 30 minutes. VS38 tissue culture supernatant was then added at a 1/1000 dilution at room temperature for 30 minutes. Filters were rinsed and then washed for 10 minutes with PBST. Filters were incubated for 30 minutes with a $1 / 750$ dilution of goat antimouse peroxidase conjugated secondary antibody (Dako, Glostrup, Denmark) in PBST, before four 15 minute washes in PBST. Antigen-antibody complexes were visualised using diaminobenzidine with metal ion enhancement. ${ }^{11}$ A second screen was performed to isolate individual positive clones.

DNA SEQUENCING

The cDNA encoding the VS38 antigen in plasmid $\mathrm{pBK}-\mathrm{CMV}$ was excised in vivo from the lambda ZAP Express vector (Stratagene) using the manufacturer's instructions to yield the plasmid pAB201. DNA sequencing was performed using M13 universal and reverse primers, a Cy5 Autoread sequencing kit, and an ALF DNA sequencer (Pharmacia, St Albans, UK).

BACTERIAL PROTEIN EXPRESSION AND DETECTION $E$ coli strain XLOLR (Stratagene) containing either plasmid pAB201 or the empty vector pBK-CMV was grown overnight in LB medium containing ampicillin at $37^{\circ} \mathrm{C} .{ }^{10}$ Next day, cultures were diluted $1 / 10$ into fresh 
medium and were allowed to grow for a further 1.5 hours. Protein expression was induced by the addition of $1 \mathrm{mM}$ IPTG. After three hours at $37^{\circ} \mathrm{C}, 1 \mathrm{ml}$ samples were removed and the cell pellets were resuspended in $100 \mu$ of SDSPAGE sample buffer. ${ }^{12}$ Samples were boiled for two minutes and run on a $12 \%$ SDS-PAGE gel $^{10}$ alongside high molecular weight rainbow markers (Amersham, Little Chalfont, UK). Proteins were transferred electrophoretically using a Semi-Phor apparatus (Hoeffer, San Francisco, USA) to PVDF membrane (Millipore UK, Watford, UK). The membrane was then incubated with undiluted hybridoma culture supernatant followed by secondary goat antimouse peroxidase conjugate as above. Antibody-antigen complexes were detected using an ECL kit (Amersham) following manufacturer's instructions.

\section{ANTIBODIES}

Mouse monoclonal antibody VS38 has already been characterised. ${ }^{7}$ Mouse monoclonal antibody MC186 was raised against whole cells from a breast cancer cell line MCF7 ADR from the Imperial Cancer Research Fund, London. Mouse monoclonal antibodies $\mathrm{G} 1 / 296^{\circ}$ and A1/59/11, both of which recognise human p63, were a kind gift from Dr H-P Hauri.

\section{TISSUES}

Tissues obtained from the cellular pathology department at the John Radcliffe Hospital were immediately snap frozen in liquid nitrogen and stored at $-70^{\circ} \mathrm{C}$. Cryostat sections $(5-8 \mu \mathrm{m})$ were then cut and collected on glass multiwell slides and dried overnight at room temperature. The slides were then fixed in acetone at room temperature and stored, wrapped in aluminium foil, at $-20^{\circ} \mathrm{C}$ until staining. Formalin fixed, paraffin wax embedded sections were cut at approximately $5 \mu \mathrm{m}$ and floated on to silane coated glass slides. These were baked, dewaxed, rehydrated, and pressure cooked for 1.5 minutes in $0.01 \mathrm{M}$ sodium citrate before transfer to buffer and immunostaining.

\section{FACS ANALYSIS}

Fresh tonsils obtained from the ENT department, Radcliffe Infirmary, were minced in ice cold RPMI-1640 (Gibco-Biocult, Paisley, Scotland). The tonsil cells were then washed in PBS containing $0.1 \%$ bovine serum albumin and resuspended to $5 \times 10^{6}$ cells $/ \mathrm{ml}$. The cells were then incubated with a monoclonal antibody for 30 minutes at $4^{\circ} \mathrm{C}$. After washing, the cells were incubated for a further 30 minutes with fluorescein isothiocyanate (FITC) conjugated goat antimouse immunoglobulin (Dako). After a final wash, the cells were fixed in $1.5 \%$ formaldehyde in PBS. Tonsil cells were also permeabilised using buffered formol saline, ${ }^{13}$ before being stained as described above. In these latter experiments, anti-vimentin (V9, Dako) was used to confirm that more than $95 \%$ of the cells had been permeabilised. The results were analysed with a FACScan flow cytometer (Becton-Dickinson, Oxford, UK) using Cell Quest software.

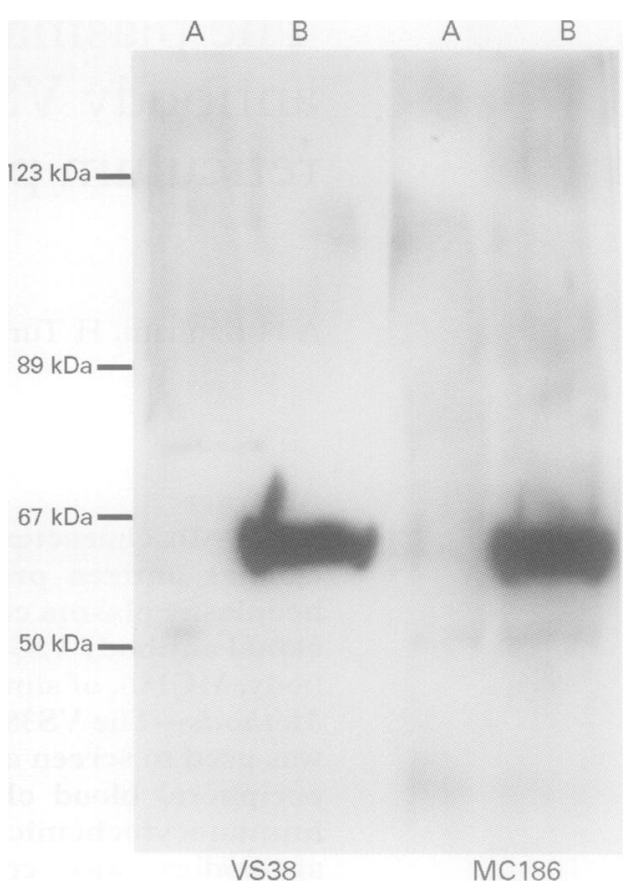

Figure 1 Western blotting with antibodies VS38 and MC186 of lysates from two cell lines. Lane A: K562 (erythroleukaemia); lane.B: A431 (vulval carcinoma). Both antibodies recognise a $64 \mathrm{kDa}$ band in the $A 431 \mathrm{cell}$ line which is not present in the K562 cell line. Molecular weight standards are indicated to the left.

\section{IMMUNOCYTOCHEMICAL STAINING} Immunoperoxidase labelling

Frozen tissue sections were incubated first with the monoclonal antibody and then with peroxidase conjugated goat antimouse (Dako). Paraffin wax embedded sections were incubated for 30 minutes in $20 \%$ normal human serum before application of the primary antibody; they were then incubated in biotin labelled goat antimouse followed by horseradish peroxidase conjugated streptavidin $\mathrm{AB}$ complex (Dako). The peroxidase reaction was developed using diaminobenzidine and slides were washed and mounted in aqueous mountant (Apathy's; BDH, Poole, UK).

\section{Results}

EXPRESSION CLONING THE VS38 ANTIGEN

One hundred thousand clones from a circulating blood cDNA library in lambda ZAP Express were screened with monoclonal antibody VS38. A single positive clone was isolated and a plasmid clone of the 1278 base pair CDNA in pBK-CMV was excised in vivo (pAB201). To confirm that this cDNA encoded the VS38 antigen, the protein encoded by plasmid pAB201 was expressed in $E$ coli. The pBK-CMV vector contains a bacterial promoter enabling expression of the cloned cDNA in $E$ coli as an in-frame fusion with $\beta$-galactosidase. The expressed protein was then western blotted with antibody VS38 and with another monoclonal antibody, MC186, which showed similar immunostaining characteristics and detected a protein of $64 \mathrm{kDa}$ by western blotting (fig 1 ). The bacterial expression data illustrated in fig 2 show that neither antibody recognised $E$ coli proteins or the $\beta$-galactosidase expressed by the empty vector pBK-CMV (lane A). Both antibodies recognised a number of different molecular weight 
B

A

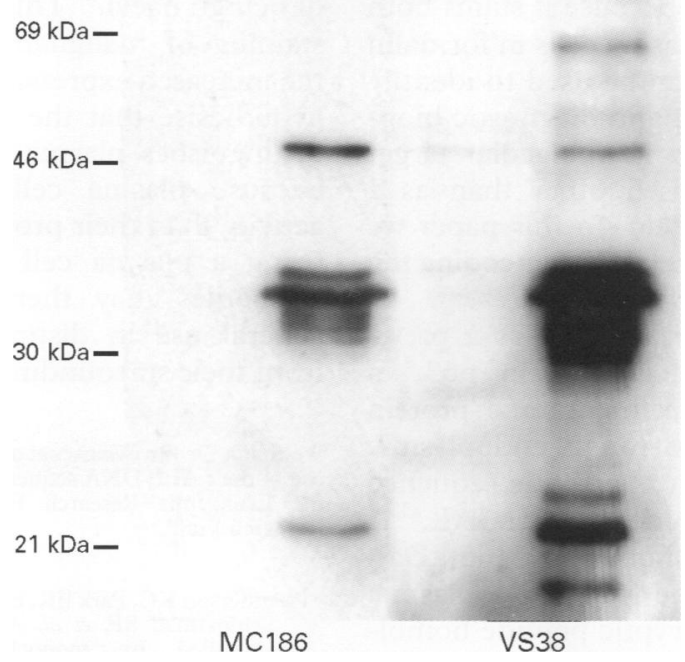

Figure 2 Western blotting of bacterially expressed proteins with antibodies MC186 and VS38. Lane A: E coli expressing $\beta$-galactosidase from the empty vector control plasmid $p B K-C M V$; lane $B$ : $E$ coli expressing recombinant protein encoded by plasmid $p A B 201$. Both antibodies recognise the recombinant protein present in lane $B$. Molecular weight standards are indicated to the left.

proteins expressed from the pAB201 cDNA clone (lane $\mathrm{B})$. The largest common band is close to the predicted molecular weight of $47 \mathrm{kDa}$ for the protein encoded by pAB201. Smaller bands probably represent degradation products. We have thus shown that both antibodies VS38 and MC186 recognise the antigen encoded by the pAB201 cDNA.

IDENTIFICATION OF THE PAB201 cDNA

The cDNA insert in plasmid pAB201 was sequenced in both directions. A search against the GenEMBL databank revealed a cDNA

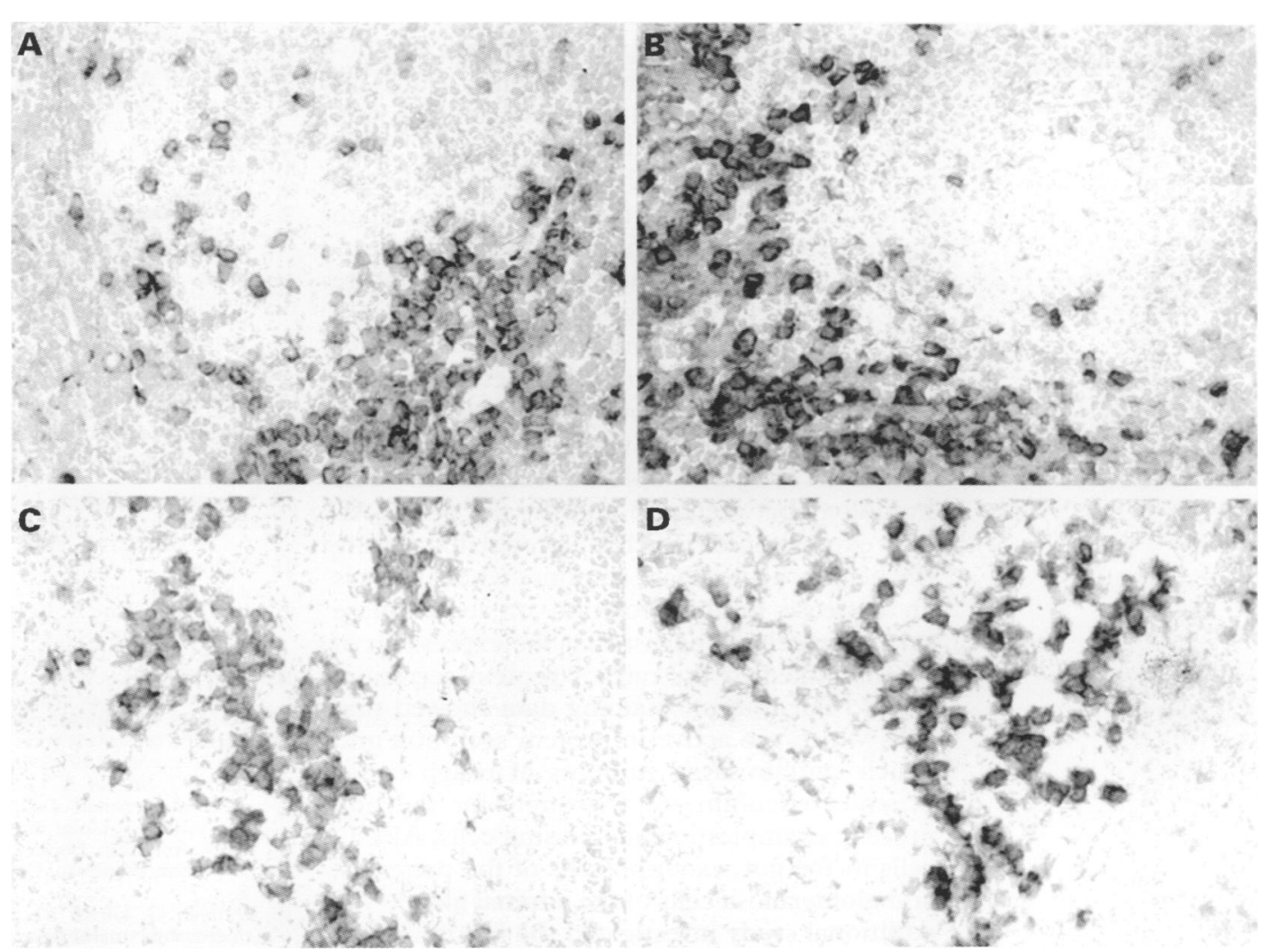

with $100 \%$ identity to the sequenced regions. This cDNA, X69910 Homo sapiens p63, encoding a transmembrane protein was cloned from a human placenta lambda gt10 library. p63 is a non-glycated, reversibly palmitoylated type II transmembrane protein ${ }^{8}$ which resides in the rough endoplasmic reticulum. ${ }^{14}$ The calculated molecular mass of $65.8 \mathrm{kDa}$ is close to the $63 \mathrm{kDa}$ determined by SDS-PAGE of p $63^{9}$ and to the value of $64 \mathrm{kDa}$ obtained in this laboratory for the protein detected by the antibodies VS38 ${ }^{7}$ and MC186 (fig 1). The cDNA clone pAB201 encodes the $C$ terminal 419 amino acids of the human p63 protein which constitute part of the 474 amino acid extracytoplasmic domain.

\section{FACS ANALYSIS}

FACS analysis of tonsil cell suspensions with and without permeabilisation confirmed that the MC186 antigen like the VS38 antigen ${ }^{7}$ is intracytoplasmic, being undetectable without prior permeabilisation. A similar FACS profile was observed with the two monoclonal antibodies raised against p63, G1/296 and A1/ 59/11 (data not shown).

IMMUNOSTAINING WITH p63 ANTIBODIES

Tissue staining with antibodies VS38 and MC186 was compared to the patterns obtained with the two antibodies to p63, G1/296 and A1/59/11. All four antibodies strongly stained plasma cells in tonsil sections and gave weaker staining of epithelium (as described for $\mathrm{VS}^{7} 8^{7}$ ) (fig 3). All four antibodies stained plasma cells in formalin fixed tissue, with differing intensities-VS38 being strongest and A1/ $59 / 11$ weakest.

Figure 3 Immunostaining of tonsil cryostat sections with antibodies VS38 (A) and MC186 (B) and with the two anti-p63 antibodies, A1/59/11 (C) and G1/296 (D), all showing staining of clusters of plasma cells. 


\section{Discussion}

Monoclonal antibody VS38 is of practical value in clinical practice because it stains both normal and malignant plasma cells in formalin fixed material and this can be used to identify myeloma or plasmacytoma in diagnostic biopsies. However, until now its molecular target has not been characterised other than as a $64 \mathrm{kDa}$ intracellular protein. In this paper we describe our cloning of the cDNA encoding the antigen recognised by VS38.

We have identified this antigen as a previously characterised human protein $\mathrm{p} 63,{ }^{8}$ a non-glycated type II transmembrane protein which is resident in the rough endoplasmic reticulum. ${ }^{14}$ p63 has high nucleotide sequence homology to a porcine gene product $3 \mathrm{AL} .{ }^{15} \mathrm{~A}$ novel rat antigen of a similar size $(65 \mathrm{kDa})$, which also localises to the rough endoplasmic reticulum, shows some tryptic peptide homology to p63.16 17

We also report in this paper a second monoclonal anti-plasma-cell antibody, MC186, which recognises the protein bacterially expressed from our partial p63 cDNA clone. The epitopes for both VS38 and MC186 must therefore be located within the $\mathrm{C}$ terminal 419 amino acids of the 474 amino acid extracytoplasmic domain. Immunostaining using antibodies VS38 and MC186-together with the monoclonal antibodies $\mathrm{G} 1 / 296$ and $\mathrm{A1} / 59 / 11$ raised against p63-show that all these antibodies recognise the same antigen in both frozen and paraffin wax embedded tissue. Our FACS analysis also confirmed that all four antibodies recognised an intracellular antigen which is consistent with the previously reported localisation of p63 to the rough endoplasmic reticulum. ${ }^{14}$

Overall the rough and smooth endoplasmic reticula are of similar lipid and protein composition, although several proteins, such as ribophorins,${ }^{18}$ the translocon associated protein complex,,$^{19}$ and the docking protein, ${ }^{21} 22$ are mainly restricted to the rough endoplasmic reticulum. The distribution of p63 in the rough endoplasmic reticulum is insensitive to organelle perturbants, such as low temperature and brefeldin A, suggesting that p63 is a resident protein. ${ }^{9}$ All three domains of the protein are required for complete retention, and oligomerisation has been proposed as the major mechanism by which p63 is retained within the rough endoplasmic reticulum. ${ }^{23}$ The homology between p63 and the pig gene 3AL (the expression of which is upregulated during the hepatic acute phase response where there is an increase in the secretion of acute phase serum proteins) suggest that the expression of p63 is linked to the rate of protein secretion. Indeed our immunostaining data showed that cells which are active in protein secretion and which contain large amounts of rough endoplasmic reticulum stain strongly for the p63 protein; examples include plasma cells, APUD cells in the gut, exocrine cells of the pancreas, and glomerulosa cells of the adrenal gland. ${ }^{7}$ An additional study investigated the immunoreactivity of a range of melanocytic lesions with antibody VS38. The authors concluded that the VS38 antigen was expressed by the majority of malignant melanomas and in a minority of benign naevi. ${ }^{24}$ This suggests that the strong staining of malignant melanomas represents the increased expression of the $\mathrm{p} 63$ protein. We hypothesise that the presence of this antigen distinguishes plasma cells from other B cells because plasma cells have more secretory activity than their progenitors, rather than p63 being a plasma cell specific antigen. These antibodies may therefore also be of more general use in distinguishing secretory cells from their surrounding tissue.

We thank Dr Jim Wainscoat and members of his laboratory for use of their ALF DNA sequencer. This work was supported by the Leukaemia Research Fund and the Imperial Cance Research Fund.

1 Anderson KC, Park EK, Bates MP, Leonard RCF, Hardy R Schlossman SF, et al. Antigens on human plasma cells identified by monoclonal antibodies. 7 Immunol $1983 ; 130: 1132-8$.

2 Nathan PD, Walker L, Hardie D, Richardson P, Khan M Johnson GD, et al. An antigenic study of human plasm cells in normal tissue and in myeloma: identification of a novel plasma cell associated antigen. Clin Exp Immunol novel plasma cell

3 Tazzari PL, Gobbi M, Dinota A, Bontadini A, Grassi G Cerato C, et al. Normal and neoplastic plasma cell membrane phenotype: studies with new monoclonal antibodies. Clin Exp Immunol 1987;70:192-200.

4 Tong AW, Lee JC, Stone MJ. Characterization of a monoclonal antibody having selective reactivity with normal and neoplastic plasma cells. Blood 1987;69:238-45.

5 Linden MD, Fishleder AJ, Tubbs RR, Park H. Immunophe notypic spectrum of plasma cell leukemia. Cancer 1989;63:

6 San Miguel JF, Gonzalez M, Gascon A, Moro MJ, Hernández JM, Ortega F, et al. Immunophenotypic heterogeneity of multiple myeloma: influence on the biology and clinica course of the disease. CastellanoLeones (Spain) Cooperative Group for the Study of Monoclonal Gammopathies. B f Haematol 1991;77:185-90.

7 Turley H, Jones M, Erber W, Mayne K, de Waele M, Gatte $\mathrm{K}$. VS38: a new monoclonal antibody for detecting plasm cell differentiation in routine sections. $f$ Clin Pathol 1994;47:418-22.

8 Schweizer A, Rohrer J, Jenö P, Demaio A, Buchman TG, Hauri H-P. A reversibly palmitoylated resident protein (p63) of an ER-Golgi intermediate compartment is related to a circulatory shock resuscitation protein. $¥$ Cell Sci 1993 ; to a circulatory

9 Schweizer A, Ericsson M, Bächi T, Griffiths G, Hauri H-P. Characterization of a novel $63 \mathrm{kDa}$ membrane protein Implications for the organization of the ER-to-Golgi pathway. $\mathcal{F}$ Cell Sci 1993;104:671-83.

10 Sambrook J, Fritsch EF, Maniatis T. In: Molecular cloning. A laboratory manual, 2 nd ed. Cold Spring Harbor: Cold Spring Harbor Laboratory Press, 1989.

11 Harlow E, Lane D. In: Antibodies. A laboratory manual. Cold Spring Harbor: Cold Spring Harbor Laboratory Press, 1988 .

12 Laemmli UK. Cleavage of structural proteins during the assembly of the head of bacteriophage T4. Nature 1970;227:680-5.

13 Slaper-Cortenbach ICM, Admiraal LG, Kerr JM, Leeuwe EF, von dem Borne A, Tetteroo PAT. Flow cytometric detection of terminal deoxynucleotidyl transferase and other intracellular antigens in combination with membran antigens in acute lymphatic leukaemia. Blood 1988;72: 1639-44.

14 Schweizer A, Rohrer J, Slot JW, Geuze HJ, Kornfeld S. Reassessment of the subcellular localization of p63. F Cell Sci 1995;108:2477-85.

15 Buchman TG, Cabin DE, Vickers S, Deutschman CS, Delgado E, Sussman MM, et al. Molecular biology of circulatory shock. Part II. Expression of four groups of hepatic tory shock. Part shock. Surgery 1990;108:559-66.

16 Chen Y-J, Hickey WF, Mezitis SGE, Steiber A, Lavi E, Gonota JO, et al. Monoclonal antibody $2 \mathrm{H} 1$ detects a $60-65 \mathrm{kD}$ membrane polypeptide of the rough ER of neurons and selectively stain cells of several rat tissues. $₹$ Historons and selectively stain cells of

17 Chen Y-J, Stieber A, Gonatas NK, Lane WS. RER-65, membrane protein of the rough ER is related to p63, a protein of an ER-Golgi intermediate compartment. Abstract 1379 American Society for Cell Biol, Annual Meeting 1994, San Francisco, California. Suppl Mol Biol Cell 1994

18 Kreibich G, Ulrich BL, Sabatini DD. Proteins of rough microsomal membranes related to ribosome binding. I Identification of ribophorins I and II, membrane protein characteristic of rough microsomes. $\mathcal{f}$ Cell Biol 1978;77: $464-87$ 
19 Vogel F, Hartmann E, Görlich D, Rapoport TA. Segregation of the signal sequence receptor protein in the rough ER membrane. Eur f Cell Biol 1990;53:197-202.

20 Hartmann E, Görlich D, Kostka S, Otto A, Kraft R, Knespel $S$, et al. A tetrameric complex of membrane proteins in the ER. Eur 7 Biochem 1993;214:375-81.

21 Hortsch M, Meyer DI. Immunological analysis of rough and smooth microsomes from rat liver: segregation of docking
protein in rough membranes. Eur f Biochem 1985;150:559protein 69.
22 Hortsch M, Griffith G, Meyer DI. Restriction of docking protein to the rough ER: immunocytochemical localization in rat liver. $\mathcal{F}$ Cell Biol 1985;38:271-9.

23 Schweizer A, Rohrer J, Hauri H-P, Kornfeld S. Retention of p63 in an ER-Golgi intermediate compartment depends on the presence of all three of its domains and on its ability to form oligomers. $\mathcal{F}$ Cell Biol 1994;126:25-39.

24 Shanks JH, Bannerjee SS. VS38 immunostaining in melanocytic lesions. F Clin Pathol 1996;49:205-7. 